\title{
Prevalence and multidrug-resistant pattern of Salmonella from the eggs and egg-storing trays of retail markets of Bangladesh
}

Tareq Mahmud ${ }^{1}$, Mohammad Mahmudul Hassan ${ }^{1}$, Mahabub Alam², Md Mamun Khan ${ }^{1}$, Md Saiful Bari ${ }^{3}$ and Ariful Islam,

1. Department of Physiology, Biochemistry and Pharmacology, Faculty of Veterinary Medicine, Chittagong Veterinary and Animal Sciences University, Khulshi, Chittagong 4225, Bangladesh; 2. Department of Animal Science and Nutrition, Faculty of Veterinary Medicine, Chittagong Veterinary and Animal Sciences University, Khulshi, Chittagong 4225,

Bangladesh; 3. Department of Dairy and Poultry Science, Faculty of Veterinary Medicine, Chittagong Veterinary and Animal Sciences University, Khulshi, Chittagong 4225, Bangladesh; 4. EcoHealth Alliance, New York, NY, USA; 5. Institute of Epidemiology, Disease Control and Research, Mohakhali, Dhaka1212, Bangladesh.

Corresponding author: Mohammad Mahmudul Hassan, e-mail: miladhasan@yahoo.com

TM: tmahmud@ymail.com, MA: mahabub38@yahoo.com, MMK: mamunksweet@gamil.com, MSB: drmsb09@gmail.com, AI: arif@ecohealthalliance.org

Received : 07-01-2016, Accepted: 22-02-2016, Published online: 24-03-2016

How to cite this article: Mahmud T, Hassan MM, Alam M, Khan MM, Bari MS, Islam A. Prevalence and multidrug-resistant pattern of Salmonella from the eggs and egg-storing trays of retail markets of Bangladesh. Int J One Health 2016;2: 7-11.

\begin{abstract}
Aim: Salmonellosis is one of the most common and widely distributed foodborne illnesses in human, and multidrugresistance of Salmonella spp. has increased in developing countries with the indiscriminate use of antibiotics in the poultry production system. A cross-sectional study was conducted on randomly selected retail markets of Chittagong City Corporation to determine the prevalence and antimicrobial resistance pattern of Salmonella isolated from commercial layer eggs, eggshell surface, and egg-storing trays.

Materials and Methods: Chicken eggs, egg surface, and egg-storing trays samples from the retail markets were collected for isolating Salmonella spp. (bacteriological culture methods) followed by antimicrobial susceptibility testing (disc diffusion method) against Salmonella isolates during the period from July to December 2013.

Results: Out of the 310 layer eggs, egg surface, and egg-storing trays samples, the highest prevalence of Salmonella spp. was found in eggs trays $(57.15 \%)$ and the lowest $(13.33 \%)$ in eggs and the prevalence differed significantly $(\mathrm{p}<0.01)$. On the other hand, the prevalence was higher (45\%) in samples of Pahartali bazar and lower (31.43\%) in samples of Bohderhat bazar but the variation among the sites was not varied significantly $(\mathrm{p}>0.05)$. Isolated Salmonella was tested for resistance to eight different antimicrobial agents, using disc diffusion method. Among eight antimicrobial tested $(\mathrm{n}=111), 100 \%$ resistance were found to ampicillin and amoxicillin followed by erythromycin (60-100\%), tetracycline (72-93\%), ciprofloxacin (22-66\%), colistin (27-66\%), enrofloxacin (42-54\%), and pefloxacin $23.07 \%$ across the study sites. Ciprofloxacin remained sensitive in $40.9 \%$ cases and, pefloxacin and colistin appeared to be almost sensitive (61-72\%) against Salmonella isolates at studied areas. Salmonella isolates showed multidrug-resistance pattern up to five of the eight antimicrobials tested.
\end{abstract}

Conclusion: It can be said that the rational use of antibiotics needs to be adopted in commercial poultry farming system of Bangladesh to prevent the emergence of drug-resistance Salmonella to protect the public health consequences.

Keywords: antimicrobial, public health, prevalence, resistance, Salmonella.

\section{Introduction}

Salmonella is one of the major bacterial agents that cause foodborne infections in humans worldwide [1]. The majority of salmonellosis outbreaks have been attributed to food such as eggs, chicken, beef, and fish to human carriers. The outbreaks involving eggs almost all have occurred in the food service sector and have been the result of inadequate refrigeration and insufficient cooking. Salmonellosis is a major problem in layer poultry in Bangladesh, and its prevalence ranged from $28 \%$ to $53.3 \%$ [2]. Among foodborne bacterial zoonoses salmonellosis causes

Copyright: Mahmud, et al. This article is an open access article distributed under the terms of the Creative Commons Attribution 4.0 International License (http://creativecommons.org/licenses/ by/4.0/), which permits unrestricted use, distribution, and reproduction in any medium, provided you give appropriate credit to the original author(s) and the source, provide a link to the Creative Commons license, and indicate if changes were made. The Creative Commons Public Domain Dedication waiver (http:// creativecommons.org/ publicdomain/zero/1.0/) applies to the data made available in this article, unless otherwise stated. huge economic losses in terms of massive morbidity and mortality [3]. Foodborne Salmonella is estimated to cause approximately 1.4 million illness, 15,000 hospitalization and 500 deaths per year in the United States [4]. The fatality rate in people infected with antibiotic-resistant Salmonella is 21 times greater than that infected with non-antibiotic-resistant Salmonella strains. Different serotypes of Salmonella including Salmonella Typhimurium and Salmonella Enteritidis are prevalent both in poultry and human and categorized as zoonotic pathogens [5]. Salmonella spp. contamination in egg producing farms and market outlets may arise at any production stage by horizontal or vertical transmission. One possible cause of Salmonella contamination in developing countries is reusable egg trays [6]. Outbreaks and sporadic cases of salmonellosis are frequently associated with the intake of infected hen eggs with Salmonella spp. The disease is endemic in many developing countries, particularly the Asian subcontinent and South and Central 
America. Antibiotic used as a therapeutic, prophylactic, or growth promoter of poultry in many developing countries including Bangladesh [7] which deposit residues in meat [8] and eggs [9]. The emergence of antimicrobial-resistant Salmonella strains is of great concern and emerging antimicrobial resistance has become a public health issue worldwide. There are reports of high prevalence of resistance in Salmonella isolates from countries such as Bangladesh $[10,11]$, India [12], and France [13]. Similarly, there are various reports of multidrug-resistant Salmonella organisms isolated from chickens eggs in Bangladesh [14].

In recent years, antibiotic resistance in Salmonella has assumed alarming issue [15], and most of the Salmonella isolated from layer birds detected earlier as are resistant to at least one antimicrobial. Moreover, antibiotic treatment is considered the most important issue that promotes the emergence, selection, and spreading of antibiotic-resistant microorganisms in both veterinary and human medicine. Evidence indicated that antimicrobial resistance among human Salmonella isolates results from the presence of antimicrobials residues in the foods [2].

This study was designed with the aim to know the prevalence and identify antimicrobials resistance against Salmonella spp. in eggs and egg-storing trays to minimize a potential public health threat.

\section{Materials and Methods}

\section{Ethical approval}

The current study was approved by Animal Ethical Experimentation Committee (CVASU-AEEC) of Chittagong Veterinary and Animal Sciences University, Bangladesh.

\section{Study area}

Six retail markets (Pahartali bazar, Jhautola bazar, Colonelhat bazar, Reazuddin bazar, Bohderhat bazar, and Alonkar bazar) of Chittagong City Corporation (CCC) were randomly selected where a large number of layer eggs are sold every day in retail markets.

\section{Study design}

A cross-sectional study was conducted in different wet markets of Chittagong, Bangladesh, to investigate the prevalence and antimicrobial resistance pattern against Salmonella spp. in egg contents, eggshell surfaces, and egg-storing trays. The study was conducted for a period of 6 months from July to December 2013.

\section{Source population and sampling frame}

Commercial markets in CCC area was used as source population. All markets of the source population also included in the sampling frame. The smallest unit of the sampling frame had sales of at least 1000 eggs/market/day. The list of the markets and other details were retrieved from the database of the CCC.

\section{Sample size calculation}

Simple random sampling was used for the sample collection, and the sample size was estimated by the formula as described by Thrusfield [16]. Out of 310 samples, fresh egg samples were 120, eggshell surface were 120 , and egg-storing tray samples were 70 .

\section{Collection and preservation of sample}

Egg-storing trays and eggshell surface

A sterile cotton swab was used to wet in sterilized normal saline solution to swab on egg-storing tray and eggshell surface then the swab was put immediately into a sterile vial containing $6 \mathrm{ml}$ Amines Transport Media (Oxoid). The individual sample in each vial was given unique identification number then immediately transferred to Poultry Research and Training Centre (PRTC) laboratory, Chittagong Veterinary and Animal Sciences University (CVASU) through ice box. Samples with transport media were stored temporarily in a refrigerator before laboratory evaluation.

\section{Egg content}

Egg samples were collected from egg trays from selected markets in CCC, live chicken, and eggs retailers shop according to FDA procedure. All samples were labeled and kept in an insulated box in the field and transported to the laboratory then stored in the refrigerator before laboratory evaluation. Eggshells were washed with normal saline solution then cracked with sterile knife and contents were taken into a jar and mixed well through stirrer.

\section{Laboratory evaluation}

A protocol followed by Hoque et al. [17] was used for the present study to perform a bacteriological culture of Salmonella spp. $1 \mathrm{ml}$ of egg surface and the egg-storing suspension was transferred into $10 \mathrm{ml}$ Mannitol Selenite Broth (Oxoid) and was incubated at $37^{\circ} \mathrm{C}$ for $18 \mathrm{~h}$. After incubation, a loop full of broth was streaked on xylose lysine deoxycholate medium and incubated at $37^{\circ} \mathrm{C}$ for $24 \mathrm{~h}$. Colonies with black centers were considered presumptive Salmonella spp. [17]. Presumptive colonies were sub-cultured in blood agar and subjected to some basic biochemical tests (urease, oxidase, and catalase) for confirmation of Salmonella.

\section{Selection of antimicrobials}

The most commonly used antimicrobial agents for either chemoprophylaxis or therapy for control of bacterial diseases in poultry in South Asia were included for antimicrobial susceptibilities such as ciprofloxacin, erythromycin, pefloxacin, tetracycline, amoxicillin, ampicillin, colistin, and enrofloxacin. These are also frequently used in Bangladesh.

\section{Antimicrobial sensitivity test}

Antimicrobial susceptibility testing against Salmonella isolates was performed using the antimicrobial disc (Oxoid) according to Kirby-Bauer antimicrobial disc diffusion techniques. Pure colonies of the Salmonella spp. isolates were inoculated in nutrient broth and incubated at $37^{\circ} \mathrm{C}$ for overnight. The isolates 
Table-1: Prevalence of Salmonella in different samples and sampling sites.

\begin{tabular}{|c|c|c|c|c|}
\hline Variables & Categories & Positive (\%) & Chi-square value & p value \\
\hline \multirow[t]{3}{*}{ Sample } & Egg-storing trays & $40(57.2)$ & 45.47 & 0.00 \\
\hline & Eggshell surface & $55(45.8)$ & & \\
\hline & Egg content & $16(13.3)$ & & \\
\hline \multirow[t]{6}{*}{ Sampling site } & Jhautola bazar & $13(32.5)$ & 3.57 & 0.61 \\
\hline & Pahartali bazar & $18(45.0)$ & & \\
\hline & Reazuddin bazar & $24(32.0)$ & & \\
\hline & Colonelhat bazar & $19(42.2)$ & & \\
\hline & Alonker bazar & $15(37.5)$ & & \\
\hline & Bohderhat bazar & $22(31.4)$ & & \\
\hline
\end{tabular}

were streaked thoroughly on the Mueller-Hinton agar using sterile glass rod $\left(60^{\circ}\right.$ cone-shaped $)$ and antimicrobial discs; ampicillin (30 mcg/disc), amoxicillin (30 $\mathrm{mcg} / \mathrm{disc})$, ciprofloxacin $(5 \mathrm{mcg} / \mathrm{disc})$, colistin (25 mcg/disc), erythromycin (15 mcg/disc), enrofloxacin $(30 \mathrm{mcg} / \mathrm{disc})$, pefloxacin $(5 \mathrm{mcg} / \mathrm{disc})$, and tetracycline $(30 \mathrm{mcg} / \mathrm{disc})$ were placed centrally using antimicrobial disc dispenser (Oxoid). The petridishes were incubated at $37^{\circ} \mathrm{C}$ for $24 \mathrm{~h}$. The plates were observed for antimicrobial susceptibility pattern by measuring the zone of inhibition according to CLSI [18], and the isolates were considered as sensitive, intermediately sensitive or resistance.

\section{Data analysis}

Descriptive analysis was performed to know the frequency and distribution of Salmonella and antibiotic resistance pattern using STATA/IC-11.0.

\section{Results}

Table-1 shows the prevalence of Salmonella spp. in different samples such as egg contents, egg-storing trays, and eggshell surfaces. The highest prevalence was found in egg-storing trays $(57.2 \%)$ and lowest $(13.3 \%)$ in egg contents. Among the category of samples, the variation in prevalence differs significantly $(p<0.01)$. On the other hand, the prevalence was higher $(45.0 \%)$ in samples of Pahartali bazar and lower (31.4\%) among the samples of Bohderhat bazar, but there were observed insignificant $(p>0.05)$ variation of prevalence among the study sites.

The prevalence and pattern of antimicrobial resistance of Salmonella isolates from egg-storing trays have been outlined in Table-2. Resistance patterns of Salmonella were the highest in amoxicillin (100\%) followed by ampicillin (97.5\%), erythromycin (90\%), tetracycline $(82.5 \%)$, enrofloxacin $(60 \%)$, colistin $(52.5 \%)$, ciprofloxacin $(27.5 \%)$, and pefloxacin $(5 \%)$. In the current research, all the isolates of Salmonella showed multiple antimicrobial resistances.

The results of antimicrobial resistance pattern against Salmonella isolated from the eggshell surface are shown in Table-2. The results revealed that the isolate from eggs shell surface was the highest resistance to ampicillin (100\%) followed by amoxicillin $(98.2 \%)$, tetracycline $(94.5 \%)$, erythromycin $(83.6 \%)$, and others $(0-50.9 \%)$. The increasing rates of resistance to ampicillin, amoxicillin, tetracycline,
Table-2: Antimicrobial resistance pattern of Salmonella isolates from egg-storing trays, eggshell surface, and egg contents.

\begin{tabular}{lccc}
\hline Antibiotics & \multicolumn{3}{c}{ Resistance pattern (\%) } \\
\cline { 2 - 4 } & $\begin{array}{c}\text { Egg-storing } \\
\text { trays (n) }\end{array}$ & $\begin{array}{c}\text { Eggshell } \\
\text { surface (n) }\end{array}$ & $\begin{array}{c}\text { Egg } \\
\text { contents (n) }\end{array}$ \\
\hline Enrofloxacin & $60.0(40)$ & $47.3(55)$ & $31.3(16)$ \\
Amoxicillin & $100(40)$ & $98.2(55)$ & $93.8(16)$ \\
Colistin & $52.5(40)$ & $50.9(55)$ & $60.0(16)$ \\
Erythromycin & $90.0(40)$ & $83.6(55)$ & $87.5(16)$ \\
Tetracycline & $82.5(40)$ & $94.5(55)$ & $62.5(16)$ \\
Ampicillin & $97.5(40)$ & $100(55)$ & $87.5(16)$ \\
Pefloxacin & $5.0(40)$ & $9.1(55)$ & $12.5(16)$ \\
Ciprofloxacin & $27.5(40)$ & $49.1(55)$ & $31.3(16)$ \\
\hline
\end{tabular}

and erythromycin among the isolates might attribute to the emergence of multi-resistance Salmonella spp.

In this study, all the egg contents isolates were tested for the susceptibility against eight different commercially available antimicrobial discs which are showed in the Table-2. Resistance spectrum of Salmonella for eight antibiotics tested were enrofloxacin (31.3\%), amoxicillin (93.8\%), colistin (43.8\%), erythromycin $(87.5 \%)$, tetracycline $(62.5 \%)$, ampicillin $(87.5 \%)$, pefloxacin $(12.5 \%)$, and ciprofloxacin (31.3\%).

\section{Discussion}

The eggshell surface contamination can occur through egg contact with fecal material, and feed or even during transportation, storage or handling. The results of the present study indicated that the prevalence of Salmonella in eggshell surface was significantly higher, and a similar finding was reported by Davies and Breslin [19].The prevalence of Salmonella was reported $40 \%$ in eggshells in a previous study carried out in Pakistan [20] and 6.1\% in India [21]. One possible cause of Salmonella contamination in developing countries is repeated use of same egg-storing trays [6]. Egg-storing trays contamination might be due to chicken fecal material or due to the environment [22]. The results of Salmonella incidence in commercial egg-storing trays were 7.5\% [21] in India. Prevalence was also recorded $43.93 \%$ in Pakistan [20] that was almost similar to current research. Salmonella prevalence is higher in egg-storing plastic trays due to the use of plastic trays for a long duration without washing 
properly or disinfecting. In this study, Salmonella was isolated about $13.33 \%$ from egg contents, which is higher than in egg contents from Dhaka city $(8 \%)$, reported earlier by Ahmed et al.[14]. In this investigation, the occurrence of Salmonella spp. among market eggs is lower than the prevalence of Salmonella spp. in egg content reported as $15.07 \%$ in Pakistan [20], $5 \%$ in North India [23], 7.7\% in Southern India [21], and $3.33 \%$ in Nigeria [24]. Research findings suggest that in 2002 the prevalence of Salmonella spp. in table eggs in some overseas countries were below $1 \%$ such as in Denmark, Germany, and the Netherlands were $0.06 \%, 0.62 \%$, and $0.01 \%$, respectively, whereas the prevalence of Salmonella spp. was above 1\% among the table eggs in some European countries such as in Austria, Greece, Italy, and Spain were $1.1 \%$, $3.8 \%, 3.1 \%$, and $8.1 \%$, respectively [25]. The major Salmonella spp. isolated during outbreaks was transferred through egg contents all over the world including Bangladesh [14].

Ciprofloxacin is extensively used against Salmonella infection in Bangladesh. The results of resistance for ciprofloxacin in this study were more or less similar with other investigations conducted in different places in Bangladesh [2,26] and other parts of the world $[7,27]$. This might be due to ciprofloxacin is naturally less resistance drug against Salmonella spp. [28]. Pefloxacin and colistin appeared to be less resistance against Salmonella spp. isolated from egg samples. This is might be due to the fact that these drugs are newly introduced and not commonly used against poultry diseases in Bangladesh. The use of antimicrobials in food animals has resulted in the development of antimicrobial resistance, through mutation and acquisition of resistance encoding genes [29]. The situation in developing countries like Bangladesh may be exaggerated by easy accessibility of antimicrobials at a cheaper price and their extensive use in poultry production system [30]. Another major setback might be the quality and potency of locally produced antimicrobial drugs; for example, there are over 80 different brands of the fluoroquinolones in Bangladesh. Thus, there is widespread availability and uncontrolled use of antibiotics poses the antimicrobial resistance in food animals and their products which are the actual threat of public health. These threats correspond to the many non-epidemiological and opportunistic earlier studies in Bangladesh [14] and India [21]. Salmonella isolate from the chicken egg and its environment showed resistance to 10 antimicrobials in the US, but the isolates of Salmonella in this study were found resistant to ampicillin, amoxicillin, erythromycin, and tetracycline. Multidrug-resistant Salmonella Typhimurium was reported in the past few decades and is frequently reported from the Indian subcontinent. Ongoing infection with Salmonella organism and use of medication at breeder level could considerably increase the prevalence of multiple resistant Salmonella in poultry rearing environment in Bangladesh. Therefore, the present study demonstrated that the Salmonella organisms were present in poultry egg and its environment and showed different antibiotic resistance pattern which may cause a serious public health problem in our country.

\section{Conclusion}

The results of the present study indicate that Salmonella-contaminated eggs are common in the retail markets of Chittagong, Bangladesh. The poor storage and handling practices of eggs at the site of sale could be a source of contamination. From the findings of this study, it is avowed that there are many resistant isolates of Salmonella against ampicillin, amoxicillin, tetracycline, enrofloxacin, and erythromycin. The excess utilization of antibiotics in the poultry farms might be the cause of increased resistance. Rational use of antibiotics in animal production and more prudent use of drugs in humans are needed. It is important to take concerted action to improve antibiotic resistance surveillance worldwide with a view to monitoring the emerging resistance genes and their transfer in both animal and human.

\section{Authors' Contributions}

TM and MMH conducted the research and actively prepared the manuscript. TM, MMH, and MA designed the work and provided the information. MMK, MSB, and AI participated in the manuscript preparation and advice during the research work. All the authors read and approved the final manuscript.

\section{Acknowledgments}

The authors are grateful to the University Grant Commission (UGC) of Bangladesh and CVASU for providing financial and technical support, respectively, to the project. This study was benefited from intellectual contributions from the PREDICT project of the United States Agency for International Development (USAID) Emerging Pandemic Threats Program.

\section{Competing Interests}

The authors declare that they have no competing interests.

\section{References}

1. Herikstad H, Motarjemi Y, Tauxe RV. Salmonella surveillance: A global survey of public health serotyping. Epidemiol Infect 2002;129:1-8.

2. Mahmud MS, Bari ML, Hossain MA. Prevalence of Salmonella serovars and antimicrobial resistance profiles in poultry of Savar area, Bangladesh. Foodborne Pathog Dis 2011;8:1111-8.

3. Hafez HM. Enteric diseases of poultry with special attention to Clostridium perfringens. Pakistan Vet J 2011;31:175-84.

4. Mead PS, Slutsker L, Dietz V, McCaig LF, Bresee JS, Shapiro C, et al. Food-related illness and death in the United States. Emerg Infect Dis 1999;5:607-25.

5. Verma JG, Gupta BR, Ghosh SS. Studies on Salmonella Virchow in vitro sensitivity test. Indian Vet J 1999;70:572-3.

6. Utrarachkij F, Pornraungwong S, Siripanichgon K, Nakajima C, Suzuki Y, Suthienkul O. Possible horizontal transmission 
of Salmonella via reusable egg trays in Thailand. Int J Food Microbiol 2012;154:73-8.

7. Enabulele SA, Amune PO, Aborisade WT. Antibiogram of Salmonella isolates from poultry in Ovia North East local government area Edo state. Nigerian J Agric Biol 2010;1:1287-90.

8. Sattar S, Hassan MM, Islam SK, Alam M, Faruk MS, Chowdhury $\mathrm{S}$, et al. Antibiotic residues in broiler and layer meat in Chittagong District of Bangladesh. Vet World 2014;7:738-43.

9. Chowdhury S, Hassan MM, Alam M, Sattar S, Bari MS, Saifuddin AK, et al. Antibiotic residues in milk and eggs of commercial and local farms at Chittagong, Bangladesh. Vet World 2015;8:467-71.

10. Ahaduzzaman M, Hassan MM, Alam M, Islam SK, Uddin I. Antimicrobial resistance pattern against Staphylococcus aureus in environmentaleffluents. Res J Vet Pract 2014;2:13-6.

11. Hassan MM, Amin KB, Ahaduzzaman M, Alam M, Faruk MS, Uddin I. Antimicrobial resistance pattern against E. coli and Salmonella in layer poultry. Res J Vet Pract 2014:2:30-5.

12. Mandal S, Mandal MD, Pal NK. Reduced minimum inhibitory concentration of chloramphenicol for Salmonella Enterica serovar typhi. Indian J Med Sci 2004;58:16-23.

13. Weill FX, Guesnier F, Guibert V, Timinouni M, Demartin M, Polomack L, et al. Multidrug resistance in Salmonella Enterica serotype Typhimurium from humans in France (1993 to 2003). J Clin Microbiol 2006;44:700-8.

14. Ahmed MM, Rahman MM, Mahabub KR, Wahiduzzaman KR. Characterization of antibiotic resistant Salmonella spp isolated from Dhaka city. J Sci Res 2011;3:191-6.

15. Murugkar HV, Rahman H, Kumar A, Bhattacharyya D. Isolation, phage typing and antibiogram of Salmonella from man and animals in northeastern India. Indian J Med Res 2005;122:237-42.

16. Thrusfield M. Veterinary Epidemiology. $3^{\text {rd }}$ ed. Oxford, UK: Blackwell Science; 2008. p. 231-2.

17. Hoque MA, Burgess GW, Greenhill AR, Hedlefs R, Skerratt LF. Causes of morbidity and mortility of wild aquatic birds at Billabong Sanctuary, Townsville, North Queensland, Australia. Avian Dis Digest 2012;7:78-9.

18. CLSI. Comparison of the Vitek 2 Antifungal Susceptibility System with the Clinical and Laboratory Standards Institute (CLSI) and European Committee on Antimicrobial Susceptibility Testing (EUCAST) broth microdilution reference methods and with the sensititre yeast one and Etesttechniques for in vitro detection of antifungal resistance in yeast isolates. J Clin Microb 2010;48:1782-6.

19. Davies R, Breslin M. Observations on Salmonella contamination of eggs from infected commercial laying flocks where vaccination for Salmonella Enterica serovar enteritidis had been used. Avian Pathol 2004;33:133-44.

20. Akhtar F, Hussain I, Khan A, Rahman SU. Prevalence and antibiogram studies of Salmonella Enteritidis isolates from human and poultry sources. Pak Vet J 2010;30:25-8.

21. Suresh T, Hatha AA, Sreenivasan D, Sangeetha N, Lashmanaperumalsamy P. Short communication: Prevalence and antimicrobial resistance of Salmonella Enteritidis and other Salmonellas in the eggs and egg-storing trays from retails markets of Coimbatore, south India. Food Microb 2006;23:294-9.

22. Bangtrakulnonth A, Pornreongwong S, Pulsrikarn C, Sawanpanyalert P, Hendriksen K, Aarestrup FM. Salmonella serovars in ovaries of layer hens at a time of slaughter. J Food Prot 2004;54:488-91.

23. Singh BR. Prevalence of Multiple Drug Resistant Salmonella and Eschericia coli in Table Eggs in North India; 2012. Available from: http://www.notoare.com/11636071. Accessed on 24-10-2015.

24. Oluwatoyin AH, Olusola AV, Olutayo BO, Olugbenga AM. Salmonella status of eggs on the market Nigeria. Int J Pharm Chem Sci 2012;1:917-22.

25. Kirk J, Atwill E, Holmberg C, Arana M, Collar C, Ghirardelli D, et al. Prevalence of and risk factors for Salmonella in water offered to weaned dairy calves in California, USA. Prev Vet Med 2002;54:169-78.

26. Islam MM, Haider MG, Chowdhury EH, Kamruzzaman M, Hossain MM. Sero prevalance and pathological study of Salmonella infection in layer chickens and isolation and identification of causal agents. Bangladesh $\mathrm{J}$ Vet Med 2006;4:79-85.

27. Eliana N, Castiglioni T, Ana MI, Greice FZ, Renato LL, Antonio GM, et al. In: Barakat SM, editor.Important aspects of Salmonella in the poultry industry and in public health, Salmonella-a-dangerous Foodborne pathogen, 2012. Available from: http://www.intechopen.com/books/ Salmonella-a-dangerous foodbornepathogen/important-aspects-of-Salmonella-in-the-poultry-industry-and-in-publichealth. Cited on 10-01-2013.

28. Munawwar AK, Priyanka S, Ahmed MM, Vaswani RB, Faheem SM. Antimicrobial susceptibility of Salmonella isolates from chicken meat samples in Dubai, UAE. Int $\mathbf{J}$ Food Nutr Public Health 2010;3:149-59.

29. Fluit AC. Towards more virulent and antibiotic-resistant Salmonella? FEMS Immunol Med Microbiol 2005;43:1-11.

30. Prakash B, Krishnappa G, Muniyappa L, Kumar BS. Epidemiological characterization of avian Salmonella Entericaserovar infections in India. Int $\mathrm{J}$ Poultry Sci 2005;4:388-95. 